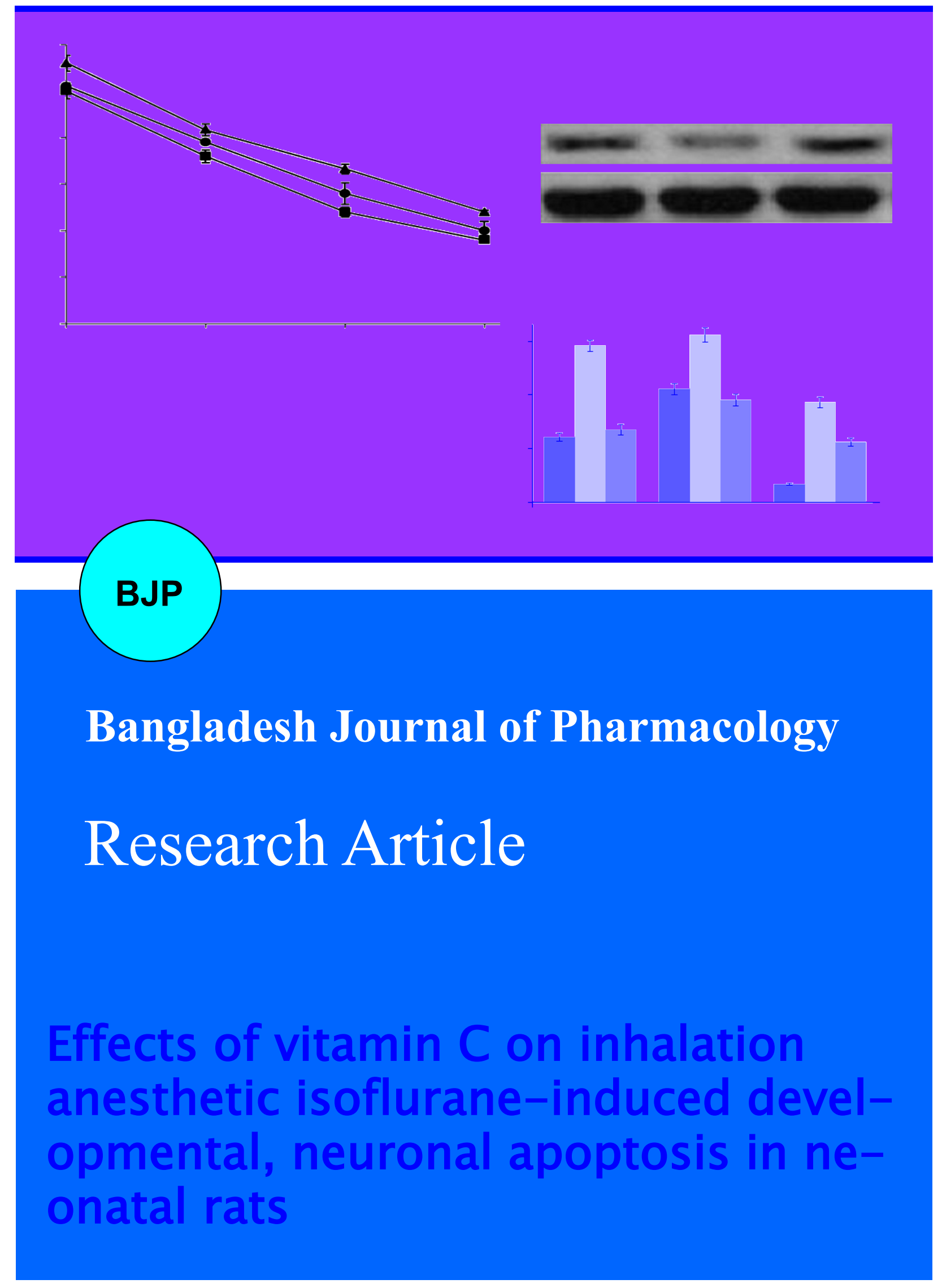




\title{
Effects of vitamin C on inhalation anesthetic isoflurane-induced developmental, neuronal apoptosis in neonatal rats
}

\author{
Yun Fei Shuai', Meng Qing Wang', Le Qin Xiong², Lin Liu3 ${ }^{3}$, Yin He Luo4 and \\ Tian Shu Peng5 \\ ${ }^{1}$ Department of Pediatrics, the First Affiliated Hospital of Hunan Traditional Chinese Medicine University, Changsha \\ 410007, China; ${ }^{2}$ State Key Laboratory of Medical Genetics, Life Science and Technology College, Central South \\ University, Changsha 410078, China; ${ }^{3}$ Department of Pediatrics, Xiangya Third Hospital of Central South University, \\ Changsha 410013, China; ${ }^{4}$ Department of Pediatric Integrative Medicine, Hunan Traditional Chinese Medicine \\ University, Changsha 410208, China; ${ }^{5}$ Department of Anorectal, the Second Affiliated Hospital of Hunan Traditional \\ Chinese Medicine University, Changsha 410005, China.
}

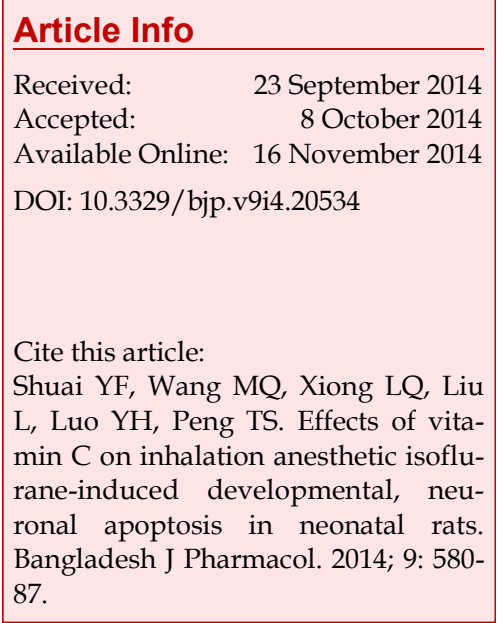

\begin{abstract}
Developmental abnormalities, neuronal apoptosis and associated cognitive impairment following isoflurane exposure in neonatal rodents have been reported. The study was undertaken to investigate the effect of vitamin $\mathrm{C}$ supplementation against isoflurane-induced neurotoxicity. Seven day old rats were exposed to $1.1 \%$ isoflurane, or air for 6 hours. Treatment groups were administered with vitamin $\mathrm{C}(30 \mathrm{mg} / \mathrm{kg}$, orally) from postnatal day 1 (P1) to P10 and were exposed to isoflurane on P7. Isoflurane exposure induced apoptosis was determined by Fluoro-Jade $C$ and terminal deoxynucleotidyltransferase-mediated 2'-deoxyuridine 5 '-triphosphate nick-end labeling assay. Vitamin C considerably improved memory and learning impairments, modulated neuroapoptosis and improved expressions of brain-derived neurotrophic factor, nerve growth factor, Bcl-xL and decreased activated caspase-3 expressions. Thus, vitamin $\mathrm{C}$ effectively offered protection against isoflurane-induced neuronal apoptosis, learning and memory disturbances.
\end{abstract}

\section{Introduction}

About 200 million patients worldwide are exposed to anesthesia and undergo surgery each year (Weiser et al., 2008; Moonesinghe et al., 2011). Volatile anesthetics such as isoflurane and sevoflurane are used in millions of young children each year during surgical procedures and imaging studies (Istaphanous and Loepke, 2009). Exposure to anesthetic cocktails (Yon et al., 2005; Lu et al., 2006; Sanders et al., 2009) or volatile agents such as isoflurane even as a single anesthetic (Yon et al., 2005; Ma et al., 2007) has been reported to be associated with widespread apoptotic neurodegeneration in the developing brains and contributes to the post-operative cognitive dysfunction (POCD) (Jevtovic-Todorovic et al., 2003; Satomoto et al., 2009; Brambrink et al., 2010; Kong et al., 2011; Paule et al., 2011; Li et al., 2013a,b).

In rodent models, the effects of anesthesia have been evaluated following exposure during a time of peak brain development and synaptogenesis, typically at postnatal day 7 (P7) (Jevtovic-Todorovic et al., 2003; Stratmann et al., 2009b; Shih et al., 2012). Apoptosis has been observed to occur acutely in the period immediately following anesthesia (Jevtovic-Todorovic et al., 2003; Istaphanous et al., 2011; Shih et al., 2012), and the thalamus and hippocampus are known areas susceptible to extensive neurodegeneration (JevtovicTodorovic et al., 2003; Satomoto et al., 2009; Shih et al., 2012). 
Retrospective studies in children younger than 4 years old exposed to surgery under general anesthesia for more than once were found to have a higher risk of developing disabilities in reading and learning (DiMaggio et al., 2011; Ing et al., 2012). These observations have led to the concern about the possible detrimental effects of the use of anesthesia and sedation in pediatric population. Thus it becomes crucial to explore the mechanisms of anesthesia-induced neurodegeneration and to identify/develop potential protecttive strategies.

Previous studies in animals have suggested that exposure to volatile anesthetics can induce oxidative stress (Nazirolu and Gunay, 1999; Nazirolu and Cay, 2001). Our body is equipped with ample cache of defenses against reactive oxygen species (ROS). Concentrations of ROS are kept under strict control by the activity of innate defense systems including enzymes and non-enzymatic anti-oxidants such as vitamins (Kovacic and Somanathan, 2008). Vitamin C protects cellular membrane lipoproteins against oxidative damage caused by toxic free radicals (Netke et al., 1997).

These anti-oxidant functions of vitamin $C$ may prevent certain types of oxidative stress due to anesthetics. Hence, we reconnoitred the protective effects of vitamin $\mathrm{C}$ on inhalation anesthetic, isoflurane-induced developmental, neuronal apoptosis in neonatal rats.

\section{Materials and Methods}

\section{Animals}

This study was approved by the Institutional animal care committee at and performed in accordance with the National Institutes of Health Guide for the Use of Laboratory Animals. Seven-day-old (P7) SpragueDawley rat pups (Guangdong Medical Laboratory Animal Co., China) weighing 15-17 g were used. Rats were exposed to $1.1 \%$ isoflurane for 6 hours (approximately 0.5 MAC) in P7 rats as determined by Orliaguet et al. (2001) in 30\% oxygen or air in a temperaturecontrolled chamber as described before (Li et al., 2013b).

Treatment groups were administered with vitamin $\mathrm{C}$ (30 mg/kg, orally) from postnatal day 1 (P1) and exposed to isoflurane on P7. Vitamin C supplementation was continued till P10. Control group pups received neither vitamin $C$ nor isoflurane but received equal volumes of saline.

All animals were sacrificed 6 hours after termination of isoflurane exposure and their hippocampi were used for western blot analysis of caspase 3 and Bcl-xL $(n=6)$ and TdT-mediated dUTP nick end labeling (TUNEL) with fluorescent dye and Fluro-Jade $C$ staining $(n=6)$. For western blot analysis of BDNF and NGF, brain tissues from the animals 48 hours following isoflurane exposure were used.

All the chemicals used in the study were purchased from Sigma-Aldrich, St. Loius, MO, USA, unless otherwise mentioned.

\section{TUNEL fluorescent assay}

For TUNEL studies, rat pups were anaesthetized with isoflurane and perfused trans-cardially with $4 \%$ paraformaldehyde. Their brains were paraffin embedded and sectioned at $6 \mu \mathrm{m}$ thickness. As described before ( $\mathrm{Li}$ et al., 2007), four to five sections (200 $\mu \mathrm{m}$ apart) for each animal at the same plane of the hippocampus were chosen for detecting apoptosis using TUNEL fluorescent method (Promega, Madision, WI, USA). The slides were protected from direct light during experiment. Hoechst was used to stain nuclei. The TUNEL positive cells in CA1, CA3 and DG regions of hippocampus were analyzed immediately with NISElements BR imaging processing and analysis software (Nikon Corporation, Japan). The densities of the TUNEL positive cells in CA1, CA3 and DG were determined by dividing the number of TUNEL positive cells by the area of that brain region.

\section{Fluro-Jade C staining}

Brains from treatment and control group rats $(n=6$ per group) were assessed for acute neuronal death. Six hours following anesthesia, animals were anesthetized and transcardially perfused with cold $4 \%$ paraformaldehyde in phosphate-buffered saline and brains were excised, postfixed, and immersed in sucrose solution. The tissues were sliced into 60 micronthickness and every other slice was mounted and stained with Fluoro-Jade C, a marker very specific for neurodegeneration (FJC, 0.001\%, Millipore, Billerica, MA, USA). FJ-positive cells were counted using Nikon Eclipse 80i microscope under 20x magnification.

\section{Western blot analysis}

For western blot analysis, the pups were anaesthetized with isoflurane and sacrificed by decapitation. Hippocampi of rats were isolated immediately on ice and then stored at $-80^{\circ} \mathrm{C}$ until used. Western blotting was performed as described by Li et al. (2013b). In brief, the protein concentrations of samples were determined using the BCA protein assay (Bio-Rad, Herts, UK). Sixty $\mu \mathrm{g}$ of sample were used in western blot analysis using primary antibodies against cleaved caspase-3, Bcl-xL at 1:2000 dilution (Cell Signaling Technology Company, USA.), brain-derived neurotrophic factor (BDNF) and nerve growth factor (NGF) at 1:200 (Santa Cruz Biotechnology, Santa Cruz, CA, USA). Images were scanned by Image Master II scanner (GE Healthcare) and analyzed using Image Quant TL software (v2003.03, GE Healthcare). The band signals of other proteins were normalized to those of $\beta$-actin using anti- 
$\beta$-actin at 1:2000 dilution (Cell Signaling Technology Company, USA.),

\section{MWM test}

Rats were trained for 4 consecutive days (postnatal days 31-34) in the Morris water maze. A plat-form (10.3 $\mathrm{cm}$ diameter) was submerged in a circular pool $(180 \mathrm{~cm}$ diameter, $50 \mathrm{~cm}$ depth) filled with warm $\left(23-25^{\circ} \mathrm{C}\right)$ water. Rats were made to perform two train-ing sessions each day. In each session, rats performed four trials in which they were released from one of four randomly assigned release points while facing the tank wall. This provided two short and two medium swims per session. Animals were allowed $60 \mathrm{sec}$ to locate the hidden platform, and if failed to locate in allotted time, they were guided to the platform. In either case, the rats were removed from the platform after $15 \mathrm{sec}$. Training sessions were conducted until the rats could locate the hidden platform in less than $15 \mathrm{~s}$ (average time per session). All trials were videotaped, and rat swim paths were recorded with ANY-maze video tracking system (Stoelting Co., Wood Dale, IL, USA), that measures the time taken (latency) to find the platform(s), as well as other behavioural information obtained during the spatial reference memory test. The animals were dried and placed beneath a heating lamp after completing each test.

\section{Cued trials}

The cued trials were performed only for postnatal rats at P35, to determine whether any non-cognitive performance impairments (e.g. visual impairments and/or swimming difficulties) were present, which might affect performance on the place or probe trials. A white curtain was placed surrounding the pool to hide the visual cues. All rats received 4 trials per day. In each trial, rats were placed in a fixed position of the swimming pool towards the wall and were allowed to swim to a platform with a rod (cue) $20 \mathrm{~cm}$ above water level randomly placed in any of the four quadrants of the swimming pool. They were allotted $60 \mathrm{sec}$ to find the platform upon which they sat for $30 \mathrm{sec}$ before being removed from the pool. If a rat did not find the platform within $60 \mathrm{sec}$, the rat was gently guided to the platform and allowed to remain there for $30 \mathrm{sec}$. The time for each rat to reach the cued platform and the swim speed was recorded and the data were analyzed.

\section{Place trials}

After completion of cued trials, the curtains were removed. The same rats were chosen to perform the place trials to determine the rat's ability to learn the spatial relationship between distant cues and the escape platform (submerged, no cue rod), that was kept in the same place for all place trials. The starting points were random for each rat. The time taken to reach the platform was recorded for each trial.

\section{Probe trials}

Probe trials were conducted 24 hours after place trials to assess the memory retention. The platform was removed from the pool and the pups were placed in the opposite quadrant. The pups were allowed to swim 60 sec and the time spent in each quadrant and the swim speed were recorded and analyzed. The data are expressed as the percent time spent in each of the four quadrants.

\section{Statistical analysis}

All the values are represented as mean $\pm \mathrm{SD}$. Values at

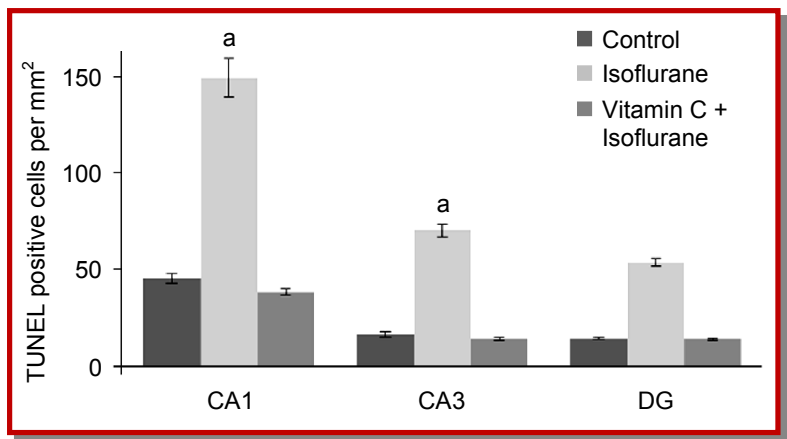

Figure 1: TUNEL positive cells in the hippocampi of P7 rats

Values are represented as mean $\pm S D, n=6$. arepresents statistical significance at $\mathrm{p}<0.05$ compared against control as determined by ANOVA

$\mathrm{p}<0.05$ are considered significant as determined by One -way Analysis of variance (ANOVA). The values were analysed using SPSS software, version 17.0.

\section{Results}

Neuroapoptosis due to exposure to isoflurane anaesthesia in the hippocampal CA1, CA3 and DG regions of P7 rat pups were assessed by TUNEL assay. Six hours exposure to isoflurane markedly $(p<0.05)$ increased the number of apoptotic cells in CA1, CA3 and in DG as compared against controls that received neither isoflurane nor vitamin C (Figure 1).

The increase in the apoptotic cells was more pronounced in the CA1 region. Vitamin C supplementation to the rat pups was observed to significantly $(p<0.05)$ reduce the number of TUNEL positive cells as against isoflurane alone exposed rat pups. In addition, FluroJade $C$ staining was also performed. The results obtained were in line with the results of the TUNEL assay. Isoflurane markedly $(\mathrm{p}<0.05)$ raised the number of the Fluro-Jade C positive cells in the CA1,CA3 and DG regions in the hippocampi of the isoflurane exposed $\mathrm{P7}$ rat pups. Vitamin C supplematation effectively $(p<0.05)$ decreased the number of apoptotic cells (Figure 2).

The levels of caspase-3 protein expression in the hippocampus of the rat pups were assessed. Isoflurane 


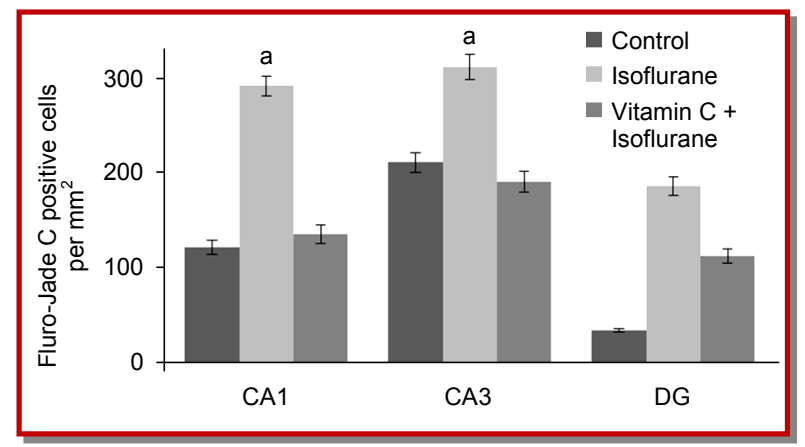

Figure 2: Fluro-Jade C positive cells in the hippocampi of P7 rats

Values are represented as mean $\pm \mathrm{SD} ; \mathrm{n}=6$; arepresents statistical significance at $\mathrm{p}<0.05$ compared against control as determined by ANOVA

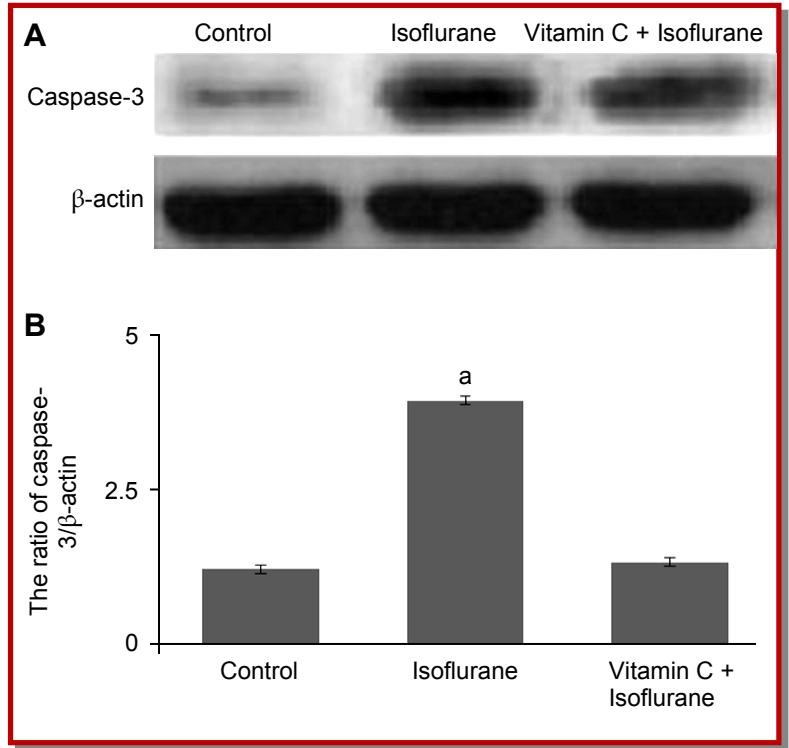

Figure 3: Expression levels of caspase-3 in the hippocampi of P7 rats

Values are represented as mean $\pm \mathrm{SD}, \mathrm{n}=6$. arepresents statistical significance at $\mathrm{p}<0.05$ compared against control as determined by ANOVA

elevated the expression of cleaved caspase- 3 markedly $(\mathrm{p}<0.05)$. Vitamin $\mathrm{C}$ supplementation decreased the expression of cleaved caspase- 3 as compared against isoflurane exposure without vitamin $\mathrm{C}$ administration (Figure 3). In addition, the expression levels of the antiapoptotic protein Bcl-xL were detected. A 2-fold decrease in Bcl-xL expression following isoflurane exposure was observed. However supplementation of vitamin C was observed to efficiently prevent the reduction in the expression levels of Bcl-xL (Figure 4).

Isoflurane exposure for 6 hours resulted in a marked decrease in the levels of growth factors (BDNF and NGF) as compared to control group. Vitamin C administration to rat pups from $\mathrm{P} 1$ was found to significantly $(p<0.05)$ increase the whole brain expression of BDNF and NGF vs isoflurane control (Figure 5). The expre-

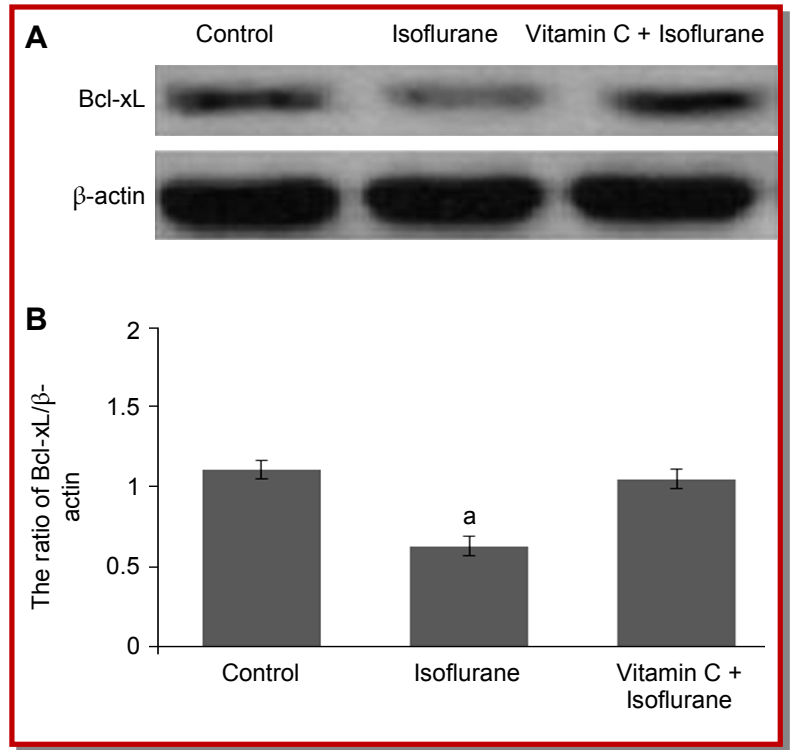

Figure 4: Expression levels of Bcl-xL in the hippocampi of P7 rats

Values are represented as mean $\pm \mathrm{SD}, \mathrm{n}=6$. arepresents statistical significance at $\mathrm{p}<0.05$ compared against control as determined by ANOVA

ssion levels of BDNF and NGF in the brain tissues of rat pups supplemented with vitamin $C$ was observed to be closer to the levels observed in control pups that were not exposed to isoflurane.

To evaluate the effect of neonatal exposure to isoflurane on potential learning and memory deficits, the rat pups were subjected to Morris water maze testing. The rat pups were trained to explore the swimming pool and to reach on the platform. The time taken to reach the platform was noted and the duration to reach up the platform was found to decrease with each training session (Figure 6A).

Cued trials were conducted at postnatal day 35 to evaluate swimming and visual abilities. The rat pups that were exposed to only isoflurane were observed to take a considerably $(p<0.05)$ longer time to reach the platform when compared to control pups that received no isoflurane. The pups that received vitamin $\mathrm{C}$ were able to reach the platform much quicker as against isoflurane control pups. (Figure 6B)

Further to establish differences in visual judgments and memory after isoflurane exposure, place and probe trials were performed. Place trials were conducted on P36 to study the ability of the rat pups to learn and remember the location of a new platform (Figure 6B). The rat pups that were supplemented with vitamin $C$ were able to reach the platform in a lesser time than the isoflurane treated rat pups. The isoflurane control pups took a longer timer to find the platform as against control pups that received neither isoflurane nor vitamin C. 


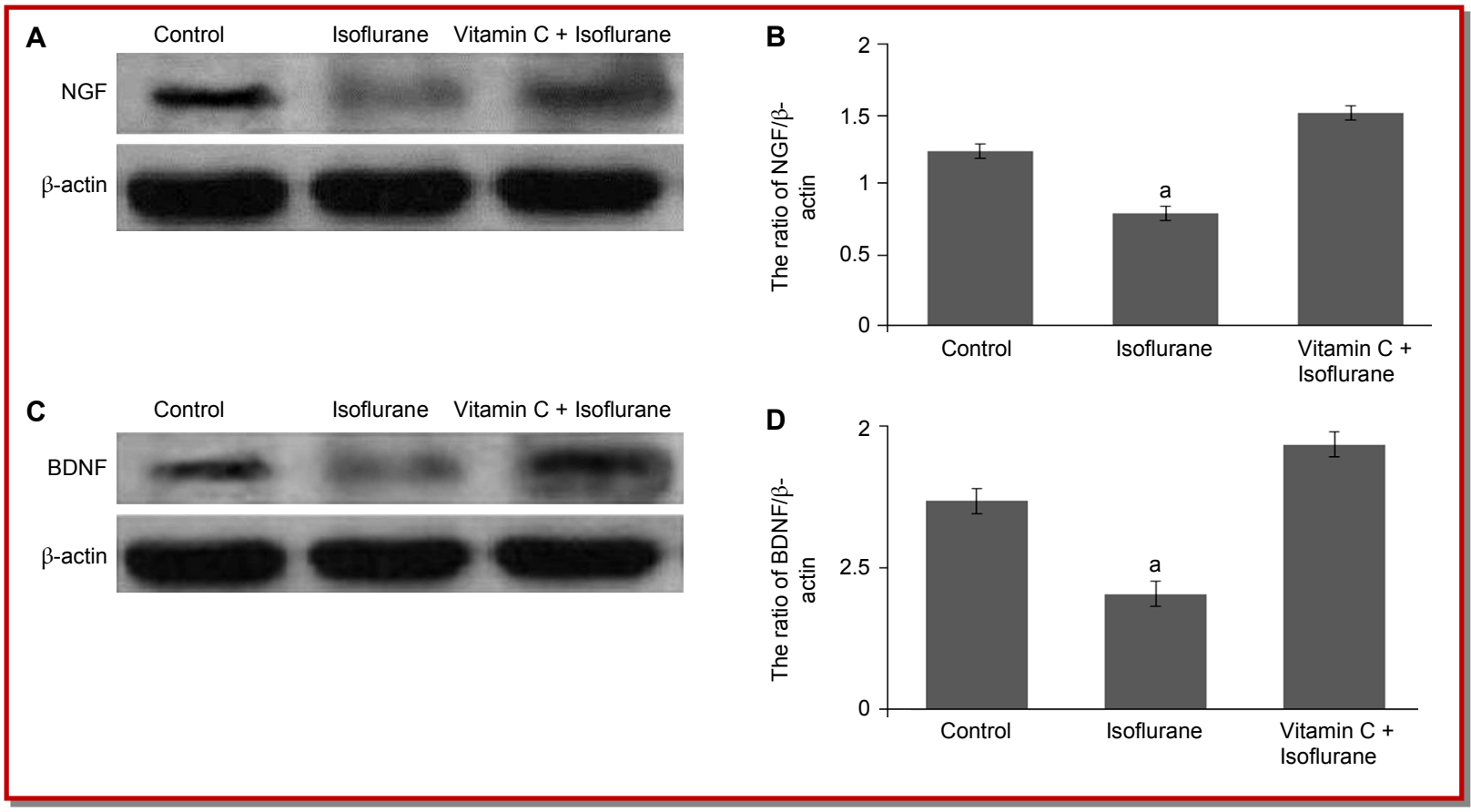

Figure 5: Expression levels of NGF (A, B) and BDNF (C, D)

Data are mean $\pm S D ; n=6$; arepresents statistical significance at $\mathrm{p}<0.05$ compared against control as determined by ANOVA

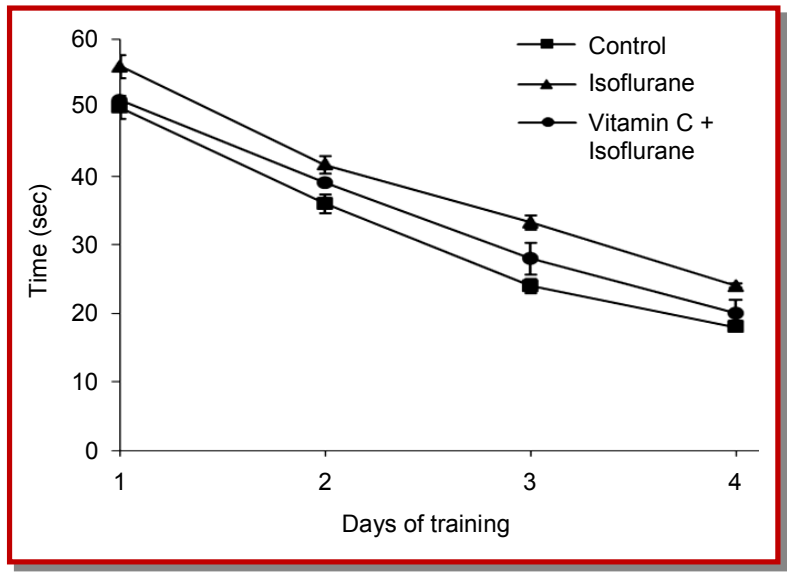

Figure 6A: Morris water maze test -Effects of anesthesia treatments on memory and learning ability

Time taken by the rat pups to reach the platform. Values are represented as mean $\pm S D(n=6)$

As demonstrated in Figure 6B, pups that were exposed to isoflurane tended to spend less percentage of time in the target quadrant than pups in the control group, with a statistically significant difference between the groups $(\mathrm{p}>0.05)$. The rat pups treated with vitamin $\mathrm{C}$ spent more time in the target quadrant. Thus the treatment with vitamin $C$ was found to have an influence on memory and learning ability of the pups.

\section{Discussion}

Isoflurane is a commonly used volatile anesthetic during surgery. Previous studies have demonstrated that it increases neuroapoptosis and induces long-term cognitive dysfunction in developing animals (Wei et al., 2005; Brambrink et al., 2010; Kong et al., 2011). The present study was undertaken to evaluate the effect of vitamin C supplementation on isoflurane induced neuronal apoptosis and alterations in memory and learning. The rat pups were exposed to isoflurane on P7. The time of exposure to isoflurane in the rats at P7 occurs during a period of peak neural development and synaptogenesis that overlaps with a corresponding stage of development in humans in the late 3rd trimester through the first several months of life (Rice and Barone, 2000).

Previous studies have demonstrated anesthesia induced cell death by apoptosis both in cell cultures (Wei et al., 2005; Xie et al., 2007) and in the developing brains (Jevtovic-Todorovic et al., 2003; Dong et al., 2009). Hippocampus has been reported to be the most sensitive region to isoflurane-induced neurotoxicity (Sanders et al., 2009). Isoflurane exposure resulted in a marked increase in neuronal apoptosis as evidenced by the results of TUNEL assay and Fluro-Jade C staining. Administration of vitamin $C$ in rat pups effectively offered neuroprotection as presented by the decrease in the number of TUNEL positive and Fluro-Jade C positive cells.

Studies have demonstrated that inhalational anesthetics induced neuroapoptosis and activated both the intrinsic and the extrinsic apoptotic pathways (Yon et al., 2005, 2006). As a step forward to understand the molecular level, we investigated the expression of caspase- 3 in the 
hippocampal regions of brains of experimental rat pups. Activation of caspase- 3 has been commonly used in these studies as a biomarker for anesthesia mediated cell death by apoptosis (Jevtovic-Todorovic et al., 2003; Dong et al., 2009). In our study, the raised levels of capase-3 following isofulrane exposure indicates neuronal apoptosis induced by isoflurane. The marked decrease in caspase- 3 expressions in the brain tissue of the rat pups supplemented with vitamin $C$ suggests the neuroprotective effects of vitamin against isoflurane induced apoptosis.

The anti-apoptotic protein Bcl-xL is widely expressed in the central nervous system (CNS) and it enhances cell survival by maintaining mitochondrial membrane integrity and inhibits the release of cytochrome C (Zhao et al., 2003). Anesthesia cocktail containing isoflurane, nitrous oxide $\left(\mathrm{N}_{2} \mathrm{O}\right)$ and midazolam was reported to downregulate $\mathrm{Bcl}-\mathrm{xL}$ expression and cause neurotoxicity in developing rat brains (Yon et al., 2005). In this study, we observed that isoflurane as a single anaesthetic also caused a decreased expression of Bcl$x \mathrm{~L}$ in the hippocampi of P7 rats. Vitamin C supplementation brought a marked raise in the expression of Bcl$x \mathrm{~L}$, thus preventing the mitochondrial membrane alteration and neuronal apoptosis. This result is in agreement with previous studies that isoflurane induced apoptosis through JNK signalling pathway and promotes apoptosis possibly via transcriptional regulation of Bcl-2 family gene, including Bcl-xL (Jeong et al., 2008; Chu et al., 2009; Li et al., 2010). Our results suggest that inhibition of Bcl-xL expression is a crucial step in the isoflurane-induced apoptosis pathway. Thus by effectively increasing the Bcl-xL expression, vitamin $\mathrm{C}$ offers protection against isoflurane induced neuroapoptosis.

Neonatal neurogenesis begins as cells proliferate, cells migrate ends as the cells integrate into a neuronal circuit as a functional neuron. It is widely believed that neurogenesis enables hippocampal plasticity and new memories (Denis-Donini et al., 2008). In addition to neuronal apoptosis, several recent studies correlate alterations in neurogenesis with cognitive performance (Zhao et al., 2008; Bianchi et al., 2010).

BDNF is a secreted protein involved in the survival, growth, and development of neurons and proper synapse formation (Bibel and Barde, 2000; Bath et al., 2013). BDNF and NGF are neurotrophins that can prevent neuronal apoptosis (Bibel and Barde, 2000). BDNF has been reported to prevent glutamate-induced apoptosis in vitro (Almeida et al., 2005) and in vivo (Husson et al., 2005). In a similar way, Nguyen et al. (2010) showed that NGF prevented staurosporine induced apoptosis on neuronal cell lines. The decrease in the levels of BDNF and NGF following 6 hours of isoflurane exposure indicates the neurotoxic effects of isoflurane. The raised expression of BDNF and NGF is indicative of the protective effects of vitamin $C$ against isoflurane induced toxic effects. The results suggest that vitamin $C$ effectively promotes neurogenesis by improving the expressions of BDNF and NGF.

Among the commonly used inhalational general anesthetics, isoflurane is widely reported to induce neurodegeneration in the developing brain and subsequent cognitive dysfunction in several animal models (Jevtovic-Todorovic et al., 2003; Sanders et al., 2010; Kong et al., 2011; Brambrink et al., 2012). In our study, we investigated the effect of supplementation of vitamin $C$ on isoflurane induced cognitive dysfunction in rat pups. Learning and memory was assessed by Morris water maze test by conducting cued, place and probe trials to judge the visual judgements, learning and memory. The results obtained suggest that vitamin C supplementation to the rats prior and post isoflurane exposure offered neuroprotection. Rat pups administrated with vitamin $C$ were observed to take a much lesser time in navigating through the pool and identifying the target platform. In addition, the pups were found to have better memory retention and better visual and spatial judgements.

The results thus suggest vitamin $C$ supplementation effectively offered protection against neuronal apoptosis by reducing the expression of caspase- 3 and increasing Bcl-xL expression. Vitamin was also found to improve neurogenesis as evidenced by elevating the expressions of neurotrophic factors-BDNF and NGF and improving the learning and memory of the rat pups as well.

\section{References}

Almeida RD, Manadas BJ, Melo CV, Gomes JR, Mendes CS, Graos MM, Carvalho RF, Carvalho AP, Duarte CB. Neuroprotection by BDNF against glutamate induced apoptotic cell death is mediated by ERK and PI3-kinase pathways. Cell Death Differ. 2005; 12: 1329-43.

Bath KG, Schilit A, Lee FS. Stress effects on BDNF expression: Effects of age, sex, and form of stress. Neuroscience 2013; 239: $149-56$.

Bianchi P, Ciani E, Guidi S, Trazzi S, Felice D, Grossi G, Fernandez M, Giuliani A, Calza L, Bartesaghi R. Early pharmacotherapy restores neurogenesis and cognitive performance in the Ts65Dn mouse model for Down syndrome. J Neurosci. 2010; 30: 8769-79.

Bibel M, Barde YA. Neurotrophins: Key regulators of cell fate and cell shape in the vertebrate nervous system. Genes Dev. 2000; 14: 2919-37.

Brambrink AM, Evers AS, Avidan MS, Farber NB, Smith DJ, Zhang X, Dissen GA, Creeley CE, Olney JW. Isofluraneinduced neuroapoptosis in the neonatal rhesus macaque brain. Anesthesiology 2010; 112: 834-41.

Brambrink AM, Back SA, Riddle A, Gong X, Moravec MD, 
Dissen GA, Creeley CE, Dikranian KT, Olney JW. Isoflurane -induced apoptosis of oligodendrocytes in the neonatal primate brain. Ann Neurol. 2012; 72: 525-35.

Chu R, Upreti M, Ding WX, Yin XM, Chambers TC. Regulation of Bax by c-Jun NH2-terminal kinase and Bcl-xL in vinblastine-induced apoptosis. Biochem Pharmacol. 2009; 78: 241-48.

Denis-Donini S, Dellarole A, Crociara P, Francese MT, Bortolotto V, Quadrato G, Canonico PL, Orsetti M, Ghi P, Memo M, Bonini SA, Ferrari-Toninelli G, Grilli M. Impaired adult neurogenesis associated with short-term memory defects in NF-kappaB p50-deficient mice. J Neurosci. 2008; 28: 3911-19.

DiMaggio C, Sun LS, Li G. Early childhood exposure to anesthesia and risk of developmental and behavioral disorders in a sibling birth cohort. Anesth Analg. 2011; 113: 1143-51.

Dong Y, Zhang G, Zhang B, Moir RD, Xia W, Marcantonio ER, Culley DJ, Crosby G, Tanzi RE, Xie Z. The common inhalational anesthetic sevoflurane induces apoptosis and increases beta-amyloid protein levels. Arch Neurol. 2009; 66: 620-31.

Husson I, Rangon CM, Lelievre V, Bemelmans AP, Sachs P, Mallet J, Kosofsky BE, Gressens P. BDNF-induced white matter neuroprotection and stage-dependent neuronal survival following a neonatal excitotoxic challenge. Cereb Cortex. 2005; 15: 250-61.

Ing $C$, DiMaggio $C$, Whitehouse $A$, Hegarty $M K$, Brady J, von Ungern-Sternberg BS, Davidson A, Wood AJ, Li G, Sun LS. Long-term differences in lan-guage and cognitive function after childhood exposure to anesthesia. Pediatrics 2012; 130: e476-85.

Istaphanous GK, Loepke AW. General anesthetics and the developing brain. Curr Opin Anesthesiol. 2009; 22: 368-73.

Istaphanous GK, Howard J, Nan X, Hughes EA, McCann JC, McAuliffe JJ, Danzer SC, Loepke AW. Comparison of the neuroapoptotic properties of equipotent anesthetic concentrations of desflurane, isoflurane, or sevoflurane in neonatal mice. Anesthesiology 2011; 114: 578-87.

Jeong HS, Choi HY, Choi TW, Kim BW, Kim JH, Lee ER, Cho SG. Differential regulation of the antiapoptotic action of Bcell lymphoma 2 (Bcl-2) and B-cell lymphoma extra long (Bcl $-x \mathrm{~L}$ ) by c-Jun $\mathrm{N}$-terminal protein kinase (JNK) 1-involved pathway in neuroglioma cells. Biol Pharm Bull. 2008; 31: 1686-90.

Jevtovic-Todorovic V, Hartman RE, Izumi Y, Benshoff ND, Dikranian K, Zorum-ski CF, Olney JW, Wozniak DF. Early exposure to common anesthetic agents causes widespread neurodegeneration in the developing rat brain and persistent learning deficits. J Neurosci. 2003; 23: 876-82.

Kong F, Xu L, He D, Zhang X, Lu H. Effects of gestational isoflurane exposure on postnatal memory and learning in rats. Eur J Pharmacol. 2011; 670: 168-74.

Kovacic P, Somanathan R. Unifying mechanism for eye toxicity: Electron transfer, reactive oxygen species, antioxidant benefits, cell signaling and cell membranes. Cell Membr Free Radic Res. 2008; 2: 56-69.
Li Y, Liang G, Wang S, Meng Q, Wang Q, Wei H. Effects of fetal exposure to isoflurane on postnatal memory and learning in rats. Neuropharmacology 2007; 53: 942-50.

Li C, Xing G, Dong M, Zhou L, Li J, Wang G, Zou D, Wang R, Liu J, Niu Y. Beta asarone protection against beta-amyloidinduced neurotoxicity in PC12 cells via JNK signaling and modulation of Bcl-2 family proteins. Eur J Pharmacol. 2010; 635: 96-102.

Li Y, Liu C, Zhao Y, Hu K, Zhang J, Zeng M, Luo T, Jiang W, Wang $H$. Sevoflurane induces short-term changes in proteins in the cerebral cortices of developing rats. Acta Anaesthesiol Scand. 2013a; 57: 380-90.

Li Y, Wang F, Liu C, Zeng M, Han X, Luo T, Jiang W, Xu J, Wang $\mathrm{H}$. JNK pathway may be involved in isofluraneinduced apoptosis in the hippocampi of neonatal rats. Neurosci Lett. 2013b; 545: 17-22.

Lu LX, Yon JH, Carter LB, Jevtovic-Todorovic V. General anesthesia activates BDNF-dependent neuroapoptosis in the developing rat brain. Apoptosis 2006; 11: 1603-15.

Ma D, Williamson P, Januszewski A, Nogaro MC, Hossain M, Ong LP, Shu Y, Franks NP, Maze M. Xenon mitigates isoflurane-induced neuronal apoptosis in the developing rodent brain. Anesthesiology 2007; 106: 746-53.

Moonesinghe SR, Mythen MG, Grocott MP. High-risk surgery: epidemiology and outcomes. Anesth Analg. 2011; 112: 891-901.

Nazirolu M, Cay M. Protective role of intraperitoneally administered vitamin $\mathrm{E}$ and selenium on the anti-oxidative defense mechanisms in rats with diabetes induced by streptozotocin. Biol Trace Elem Res. 2001; 79: 149-59.

Nazirolu M, Gunay C. The levels of some anti-oxidant vitamins, glutathione peroxidase and lipoperoxidase during the anaesthesia of dogs. Cell Biochem Funct. 1999; 17: 20712.

Netke SP, Roomi MW, Tsao C, Niedzwiecki A. Ascorbic acid protects guinea pigs from acute aflatoxin toxicity. Toxicol Appl Pharmacol. 1997; 143: 429-35.

Nguyen TL, Kim CK, Cho JH, Lee KH, Ahn JY. Neuroprotection signaling pathway of nerve growth factor and brainderived neurotrophic factor against staurosporine induced apoptosis in hippocampal H19-7/IGF-IR. Exp Mol Med. 2010; 42: 583-95.

Orliaguet G, Vivien B, Langeron O, Bouhemad B, Coriat P, Riou B. Minimum alveolar concentration of volatile anesthetics in rats during postnatal maturation. Anesthesiology 2001; 95: 34-39.

Paule MG, Li M, Allen RR, Liu F, Zou X, Hotchkiss C, Hanig JP, Patterson TA, Slikker WJ, Wang C. Ketamine anesthesia during the first week of life can cause long-lasting cognitive deficits in rhesus monkeys. Neurotoxicol Teratol. 2011; 33: 220-30.

Rice D, Barone Jr. S. Critical periods of vulnerability for the developing nervous system: Evidence from humans and animal models. Environ Health Perspect. 2000; 108(Suppl. 3): 511-33.

Sanders RD, Xu J, Shu Y, Januszewski A, Halder S, Fidalgo A, 
Sun P, Hossain M, Ma D, Maze M. Dexmedetomidine attenuates isoflurane-induced neurocognitive impairment in neonatal rats. Anesthesiology 2009; 110: 1077-85.

Sanders RD, Sun P, Patel S, Li M, Maze M, Ma D. Dexmedetomidine provides cortical neuroprotection: impact on anaesthetic-induced neuroapoptosis in the rat developing brain. Acta Anaesthesiol Scand. 2010; 54: 710-16.

Satomoto M, Satoh Y, Terui K, Miyao H, Takishima K, Ito M, Imaki J. Neonatal exposure to sevoflurane induces abnormal social behaviors and deficitsin fear conditioning in mice. Anesthesiology 2009; 110: 628-37.

Shih J, May LD, Gonzalez HE, Lee EW, Alvi RS, Sall JW, Rau V, Bickler PE, Lalchandani GR, Yusupova M, Woodward E, Kang H, Wilk AJ, Carlston CM, Mendoza MV, Guggenheim JN, Schaefer M, Rowe AM, Stratmann G. Delayed environmental enrichment reverses sevoflurane induced memory impairment in rats. Anesthesiology 2012; 116: e586-e602.

Stratmann G, Sall JW, May LD, Bell JS, Magnusson KR, Rau V, Visrodia KH, Alvi RS, Ku B, Lee MT, Dai R. Isoflurane differentially affects neurogenesis and long-term neurocognitive function in 60-day-old and 7-day-old rats. Anesthesiology 2009b; 110: e834-48.

Wei H, Kang B, Wei W, Liang G, Meng QC, Li Y, Eckenhoff RG. Isoflurane and sevoflurane affect cell survival and BCL-
2/BAX ratio differently. Brain Res. 2005; 1037: 139-47.

Weiser TG, Regenbogen SE, Thompson KD, Haynes AB, Lipsitz SR, Berry WR, Gawande AA. An estimation of the global volume of surgery: A modelling strategy based on available data. Lancet 2008; 372: 139-44.

Xie ZC, Dong YL, Maeda U, Moir RD, Xia WM, Culley DJ, Crosby G, Tanzi RE. The inhalation anesthetic isoflurane induces a vicious cycle of apoptosis and amyloid betaprotein accumulation. J Neurosci. 2007; 27: 1247-54.

Yon JH, Daniel-Johnson J, Carter LB, Jevtovic-Todorovic V. Anesthesia induces neuronal cell death in the developing rat brain via the intrinsic and extrinsic apoptotic pathways. Neuroscience 2005; 135: 815-27.

Yon JH, Carter LB, Reiter RJ, Jevtovic-Todorovic V. Melatonin reduces the severity of anesthesia induced apoptotic neurodegeneration in the developing rat brain. Neurobiol Dis. 2006; 21: 522-30.

Zhao H, Yenari MA, Cheng D, Sapolsky RM, Steinberg GK. Bcl -2 overexpression protects against neuron loss within the ischemic margin following experimental stroke and inhibits cytochrome c translocation and caspase-3 activity. J Neurochem. 2003; 85: 1026-36.

Zhao C, Deng W, Gage FH. Mechanisms and functional implications of adult neurogenesis. Cell 2008; 132: 645-60. 